IP Periodica Polytechnica

Transportation Engineering

43(2), pp. 81-86, 2015

DOI: $10.3311 /$ PPtr. 7593

Creative Commons Attribution (i)

RESEARCH ARTICLE

\section{Peculiarities of Infrastructure Designing for the Movement of Individual Environmental Friendly Vehicles}

\author{
Tetyana Lytvynenko ${ }^{1 *}$, Lina Gasenko ${ }^{1}$
}

Received 30 June 2014

\begin{abstract}
This article discusses the benefits that using of the individual ecological-friendly vehicles (IEV) brings to the inhabited locality. The examples of these transport modes with a short description of their functionality are shown here. The article analyzes the features of IEV and describes the requirements for the street and road infrastructure to provide a comfortable movement of such means of transport. Several variants of including the IEV movement into the street and road network of a settlement are proposed.
\end{abstract}

\section{Keywords}

individual environmental-friendly vehicle, bicycle infrastructure, street and road network

\footnotetext{
${ }^{1}$ Department of Highways, Geodesy and Architecture of Rural Buildings, Poltava National Technical Yuriy Kondratyuk University, Ukraine

*Corresponding author, email: kpadisb@gmail.com
}

\section{Prerequisites for the IEV using in the street and road network of the settlement}

Increasing number of personal vehicles in city streets, infrastructure settlements is aimed first of all at the motorists' needs, is accompanied by negative changes in the conditions of human life (Bruun, 2013; Massami, 2013).

Individual (designed for 1-2 people) environmental-friendly (they don't harm the environment) vehicles (IEV) are becoming increasingly popular in developed countries. The most common of them is still a bicycle (Grodach, 2012).

The using of IEV brings a number of positive changes (Carreno et al., 2014; Marta V. Faria et al., 2014) (Fig. 1):

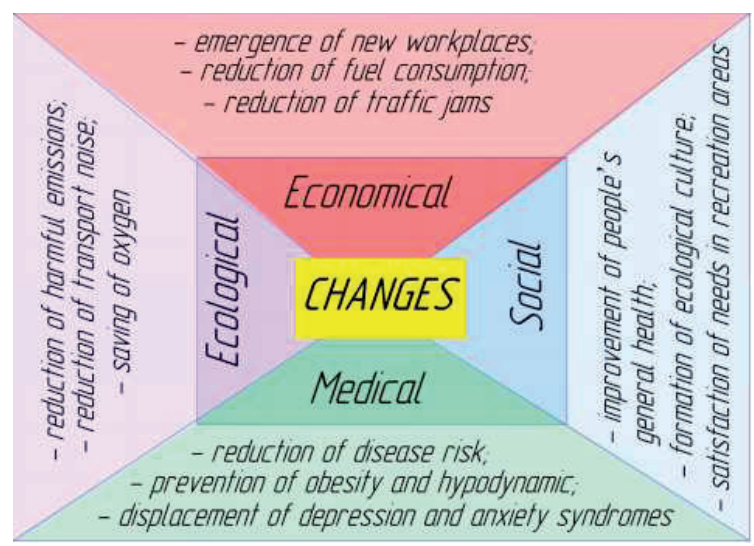

Fig. 1 Positive changes that IEV using brings to settlements

- in the medicine: the risks of coronary heart disease of inhabitants and hypertension are reduced, the problem of low mobility and predominantly sedentary lifestyle is solved, syndromes of depression and anxiety (Galiza and Ferreira, 2014) are displaced;

- in the ecology: emissions of harmful substances into the environment and the noise in localities are reduced (Bal and Kocyiğit, 2012);

- in the economy: the expenses for the fuel consumption are reduced, the amount of traffic jams decreases, new workplaces appear (because of the work activation of the factories producing new types of transport, shops, dealing with their repair, etc.); 
- in the social sphere: the well-being of inhabitants is improved, their need in organized recreation areas is satisfied (Kratochvíl, 2011), the ecological thinking is formed.

The analysis of the history of the settlements planning in context of vehicles development (Pilsitz, 2012) (see Fig. 2) shows that after the stage of motorization the logical step is the search for new means of transport, designed to solve the problems of pollution, traffic jams (Siemiatycki, 2012) and diseases associated with the sedentary lifestyles (Kampf et al., 2012).

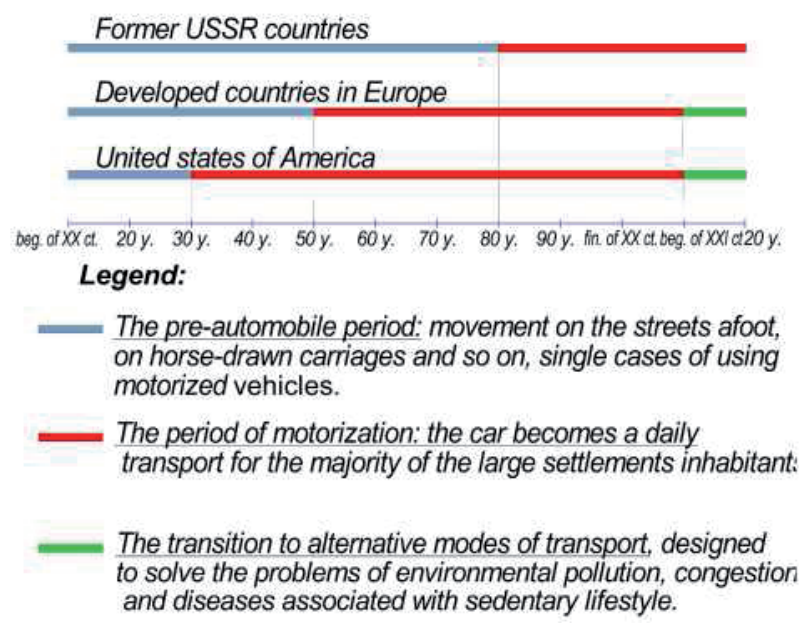

Fig. 2 The chronology of transport development in settlements

\section{Examples of individual environmental-friendly vehicles that can be used in the settlements}

The most common IEV is now a bicycle (Fig. 3), the intensity of the movement of which is growing in developed countries (Cheng and Liu, 2012).
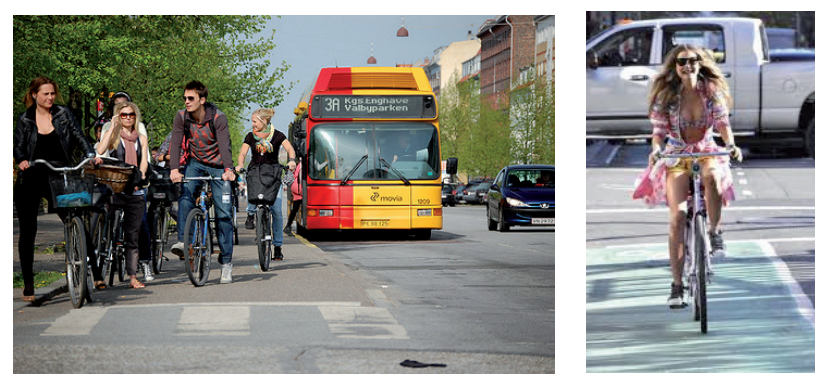

Fig. 3 The use of bicycles in the settlements

The researchers also are actively working on new various types of IEV (Mwakalonge et al., 2014).

Already now in Europe and the USA is actively used Segway - individual environmental-friendly vehicle that is a small platform on two wheels with an electric motor (Fig. 4). Control by it is done by moving the center of gravity.

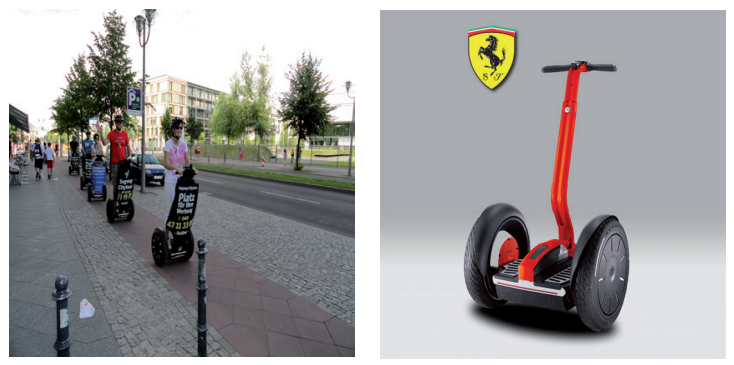

Fig. 4 Individual vehicle Segway

The concept of scooter Nissan (Fig. 5) is developed by designer Shane Krozer from Australia. According to the project the Nissan Mori scooter must be equipped with an electric motor and its management should be carried out using an onboard computer with display, located on the handlebars.

Automobile concern Honda Motor Company presented an experimental vehicle Honda UX-3. It can move back and forth, left and right and on a diagonal. The whole structure weighs less than $10 \mathrm{~kg}$, seat and footrest are composed inside the vehicle (Fig. 6).

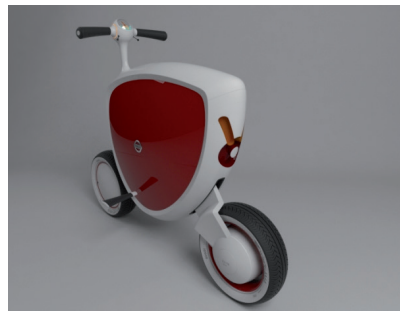

Fig. 5 Scooter Nissan Mori

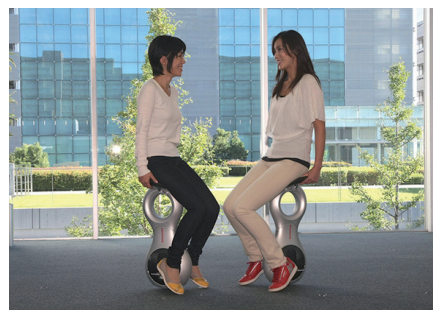

Fig. 6 Experimental vehicle Honda
The engineers of company Land Surf Inc invented the scooter with pedals Pumgo Scooter (Fig. 7), which differs from the Segway and bicycles by its increased compactness.

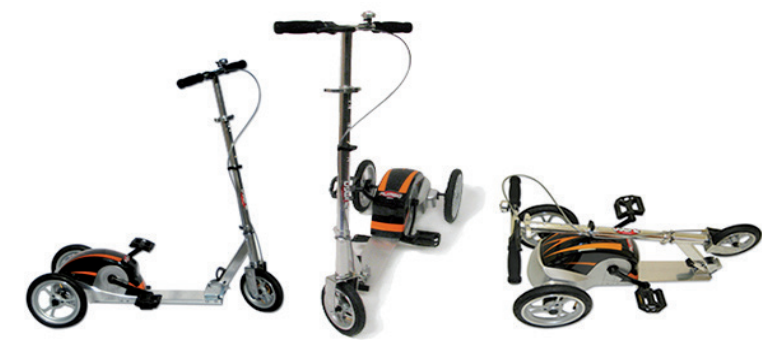

Fig. 7 Scooter with pedals Pumgo Scooter

Cyclist enthusiast of Berlin resident of Stefan Galas invented man-motor hybrid motorcycle eROCKIT (see Fig. 8), which combines the advantages of motorcycle sport bike and sustainability.

The cyclist enthusiast Berliner Stefan Galas invented a manmotor hybrid motorcycle eROCKIT (Fig. 8), which combines the benefits of a sport motorcycle and environmental safety of bike. When driving on a hybrid motorcycle you need to pedal all the time. Handles or pedals gases eROCKIT are not present - you can increase the speed by more intensive pedaling. 
Non traditional Electric Bike YikeBike Fusion Carbon (see Fig. 9) does not cause any harm to the environment. On one charging, which lasts for 45 minutes, he is able to overcome a distance of more than 10 kilometers, developing speed to $23 \mathrm{~km} / \mathrm{h}$. It can be easily and quickly composed, allowing the owner to carry their vehicle in the bag.

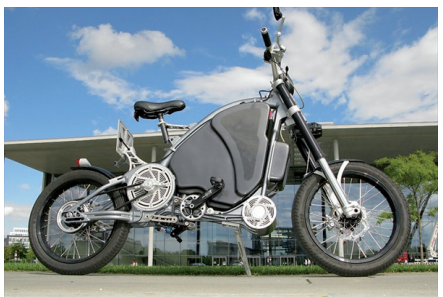

Fig. 8 Man-motor hybrid motorcycle eROCKIT

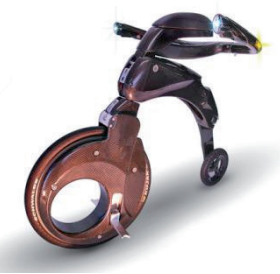

Fig. 9 Compound electric bike YikeBike Fusion Carbon
Unfortunately, the road network of settlements is poorly adapted for the general use of such modes of transport in domestic, industrial, travel and recreational purposes.

Considering the specific characteristics of IETZ, for its wide use is necessary to ensure their convenience and safety. The creation of convenient traffic conditions IETZ in the road network of the settlement requires study, analysis and systematization of the design features of the infrastructure for the movement of individual environmental-friendly vehicles.

Among the qualities that unite the listed above individual environmental vehicles, we can highlight the advantages and disadvantages of these modes of transport compared to cars (see Fig. 10).

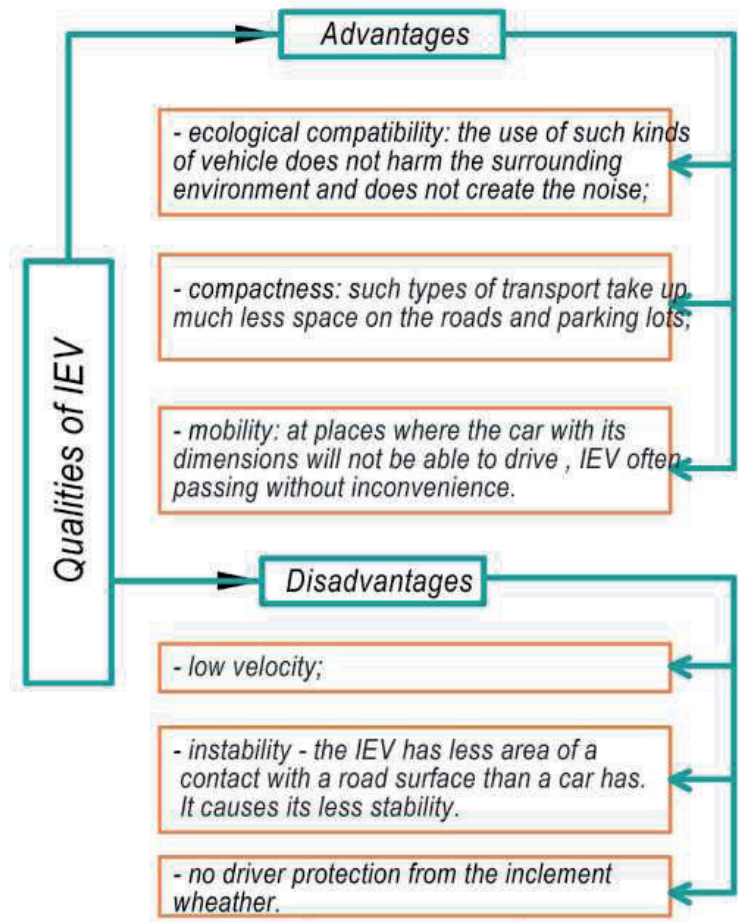

Fig. 10 The analysis of environmental-friendly individual vehicles qualities

\section{Design features of infrastructure for the IEV movement}

Considering the above such design features of the infrastructure for the movement of the vehicles can be formulated:

1. When designing this infrastructure it's necessary to take care as it's possible about the drivers' protection from harmful exhaust emissions and road noise (Griskeviciene et al., 2013).

2. The compactness and portability of IEV allowes to design the ways for their movement on the areas where the space limitations do not allow to pave roads.

3. The relatively low IEV velocity makes it necessary to achieve the shortest path (that will achieve terminals in terms that do not exceed the length of car journeys (Caris et al., 2008), the completeness and logic of routes (Broacha, 2012).

4. Based on a small area of contact of IEV with the road the particular attention should be paid to equality, roughness and adhesion of road surfaces.

5. As most of IEV does not provide driver protection from rain, it should be consider in infrastructure designing. For example there are organized special sheds over cycle tracks before traffic lights, on bicycle parking and rental locations in European countries.

It's discovered that to provide a comfortable movement of individual environmental vehicles is necessary to solve a number of issues (see Fig. 11).

A result of researches determined that the infrastructure for the movement of IEV (including bicycles) has to have the following components:

- road markings (separating stripes, icons ,bicycle”, marking of waiting areas, stops, etc.);

- road signs («path for cyclists», «path for pedestrians and cyclists», «shared bike and walking path», «start of cycling street», «cyclists are allowed to move» etc.);

- the pavement of cycle paths and traffic lanes (marked in color or texture, with enough roughness and adhesion);

- lowered curbs or ramps to overcome the height difference;

- bicycle traffic lights (with signals made in the shape of bike silhouette or conventional tricolor lights, equipped with a special sign, perhaps with digital panel);

- cycling tunnels, bicycle overpass, bridges for cyclists, bike lifts, etc.;

- bicycle parkings, stops, rental points;

- bicycle service stations, points of tire inflation, etc. 


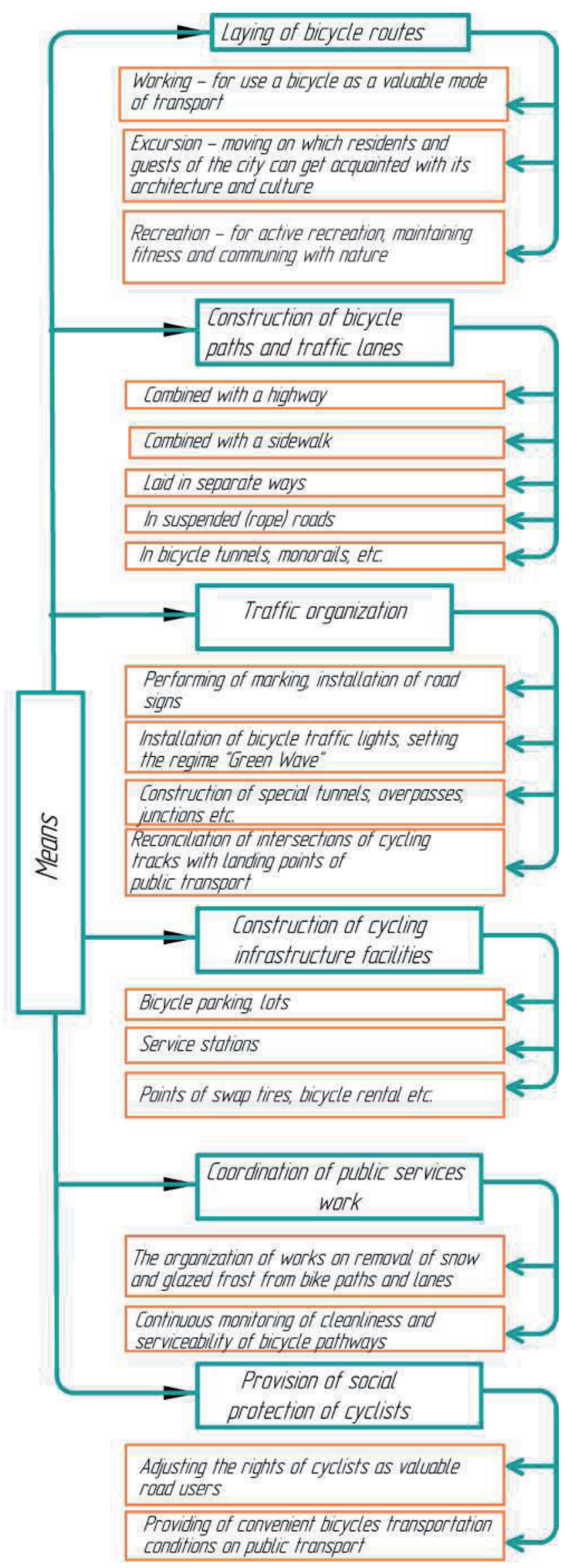

Fig. 11 Ways to provide comfortable movement of IEV
Based on the analysis of world experience designing cycling infrastructure can highlight the main techniques of bicycle traffic organization in a settlement (see Fig. 12).

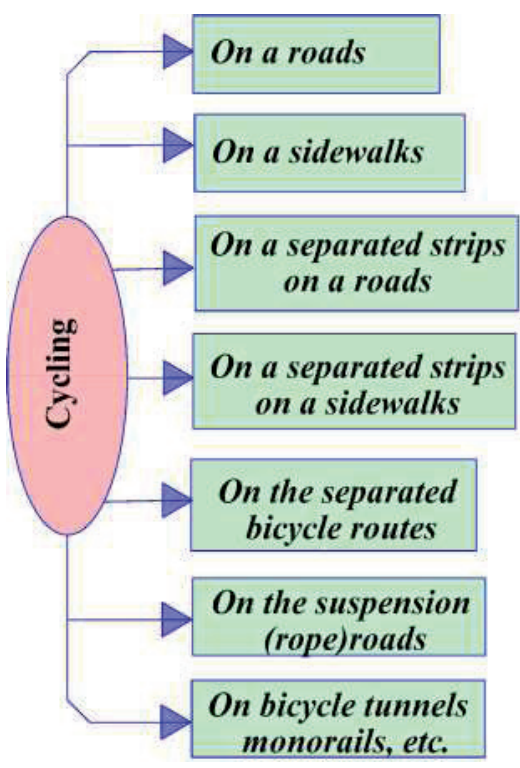

Fig. 12 Methods of cycling organization

When choosing the method of the cycling organization we should consider a number of factors (Fig. 13).

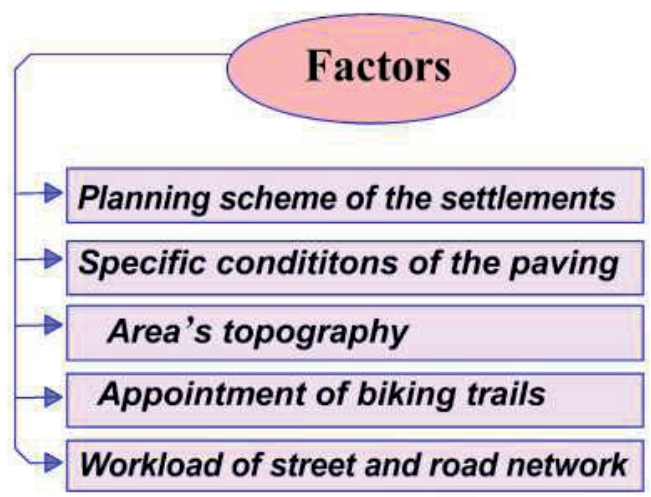

Fig. 13 Factors that influence on the choice of method of the cycling organization

Consider, for example, a typical cross-section of the main residential street (Fig. 14). Different variants of including bike paths and lanes into the profile are offered (Fig. 15-18).

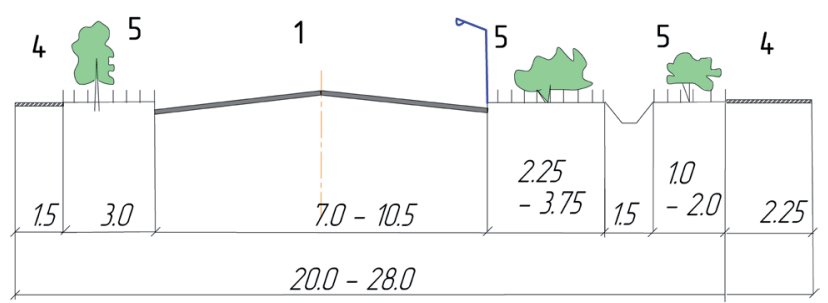

Fig. 14 Typical cross-section of the main residential street (by DBN V.2.3-5 -2001. «Streets and roads of settlements») 


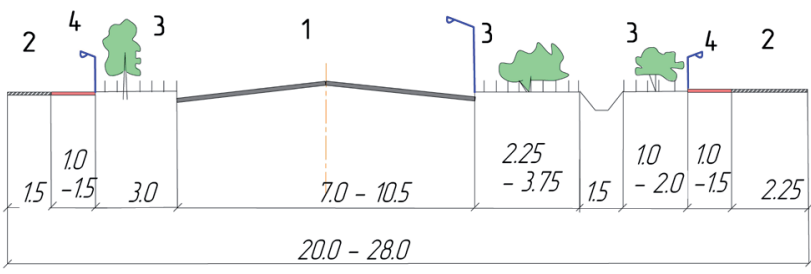

a)

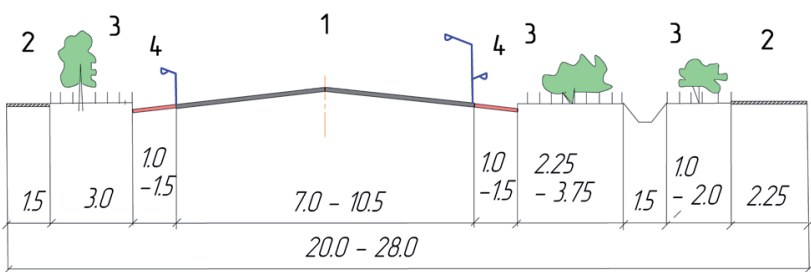

b)

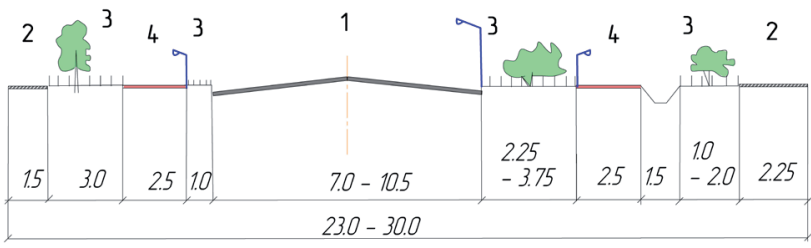

c)

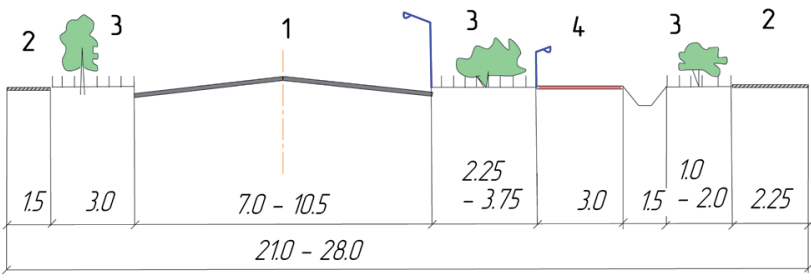

d)

Legend: $\mathbf{1}$ - the main roadway; $\mathbf{2}$ - the sidewalk; $\mathbf{3}$ - the dividing and greening strip; 4 - the cycle lane.

Fig. 15 Variants of supplement the typical cross-section of the main residential street by cycling infrastructure elements:

a) the cycle lane combined with the sidewalk;

b) the cycle lane combined with the roadway;

c) one-way bike paths;

d) two-way bike paths

Proposed profiles satisfy the requirements applicable to the street and road (including cycling) infrastructure in DBN V.2.3-5 -2001. «Streets and roads of settlements» and DBN $360-92 * *$ «Planning of cities and villages».

\section{Conclusion}

1. The use of individual environmental vehicles of the road structure settlement entails a number of positive changes. To date, the most widespread IEV is bike.

2. The implementation of cycling infrastructure not only solves the problems of today, but also prepares a settlement to the future progress in the field of vehicles (Simon, 1992).

3. In designing the infrastructure for IEV traffic it is necessary to consider their environmental friendliness, compactness, portability, low speed, instability and the driver's insecurity from rain.
4. To provide a comfortable IEV movement it is required: to lay bike trails, bike paths and lanes, to organize means of traffic, to build cycling infrastructure facilities, to coordinate the work of the municipal services (Lampis, 2013), and to provide the social protection of cyclists (Domhard, 2013).

5. Depending on the specific urban conditions, the workload of the road network, terrain and the appointment of bicycle routes should be chosen methods of cycling. The main techniques are: movement on the roads; on the sidewalks; on the bicycle lanes, combined with roads; on the bicycle lanes, combined with sidewalks; on separated cycle tracks (single or bilateral); in the bicycle tunnels, monorails, suspended (rope) roads, etc.

\section{References}

Bal Kocyiğit, F. (2012) Noise factors in healthcare facilities. Journal of the faculty of architecture. 29 (2). pp. 351-368.

DOI: 10.4305/METU. JFA.2012.2.16.

Broacha, J., Dilla, J., Gliebe, J. (2012) Where do cyclists ride? A route choice model developed with revealed preference GPS data. Transportation Research Part A: Policy and Practice. 46 (10). pp. 1730-1740.

DOI: $10.1016 /$ j.tra.2012.07.005

Bruun, E. (2013) Book 'transforming urban transport: the ethics, politics, and practices of sustainable mobility' review. Transport. 28 (2). pp. 214-216. DOI: $10.3846 / 16484142.2013 .790744$

Caris, A., Macharis, C., Janssens, G. (2008) Planning Problems in Intermodal Freight Transport: Accomplishments and Prospects. Transportation Planning and Technology. 31(3). pp. 277-302.

DOI: 10.1080/03081060802086397

Carreno, M., Ying-En. G., Borthwick, S. (2014) Could green taxation measures help incentivize future Chinease car drivers to purchase low emission vehicles?. Transport 29 (3). pp. 260-268. DOI: $10.3846 / 16484142.2014 .913261$

Cheng, Y.-H., Liu, K-C. (2012) Evaluating bicycle-transit users' perceptions of intermodal inconvenience. Transportation Research Part A: Policy and Practice. 46 (10). pp. 1690-1706. DOI: 10.1016/j.tra.2012.10.013

Domhardt, K. (2013) Continuation of a planning tradition: The social agenda of the «functional city». Architektúra \& urbanizmus. 47 (3-4). pp. 200-213.

Faria, M. V., Baptista, P. C., Farias, T. L. (2014) Electric vehicle parking in European and American context: Economic, energy and environmental analysis. Transportation Research Part A: Policy and Practice. 64. pp. 110-121. DOI: 10.1016/j.tra.2014.03.011

Galiza, R., Ferreira, L. (2014) Converting mixed pedestrian flows into equivalent commuters using standard pedestrian equivalent factors. Transportation Planning and Technology. 37 (3). pp. 235-246. DOI: $10.1080 / 03081060.2013 .875275$

Griskeviciene, D., Griskevicius, A., Griskeviciute-Geciene, A. (2013) A New Approach to Assessment of Infrastructure Projects on Urban Transport Systems. Transport and Telecommunication Journal. 13 (2). pp. 108 121. DOI: $10.2478 / \mathrm{v} 10244-012-0009-5$

Grodach, C. (2012) Cultural Economy Planning in Creative Cities: Discourse and Practice. International Journal of Urban and Regional Research. 37 (5). pp. 1747-1765. DOI: 10.1111/j.1468-2427.2012.01165.x 
Kampf, R., Gašparik J., Kudláčková, N. (2012) Application of different forms of transport in relation to the process of transport user value creation. Periodica Polytechnica Transportation Engineering. 40 (2). pp. 71-75. DOI: $10.3311 /$ pp.tr.2012-2.05

Kratochvíl, P. (2011) Public space as an architectural and social problem. Architektúra \& urbanizmus. 45 (3-4). pp. 144-165.

Lampis, A. (2013) Cities and Climate Change Challenges: Institutions, Policy Style and Adaptation Capacity in Bogotá. International Journal of Urban and Regional Research. 37 (6). pp. 1879-1901. DOI: 10.1111/1468-2427.12034

Massami, E. P. (2013) Evaluation of road traffic congestion in dar es city based on fuzzy sets. International Journal of Traffic and Transport Engineering. 2 (6). pp. 142-148. DOI: 10.5923/j.ijtte.20130206.02
Mwakalonge, J., White, J., Suihi S. (2014) Distracted Biking: A Review of the Current State-of-Knowledge. International Journal of Traffic and Transport Engineering. 3 (2). pp. 42-51. DOI: 10.5923/j.ijtte.20140302.02

Pilsitz, M. (2012) On the industrial urban development of pest in the 19th century. Periodica Polytechnica Architecture. 43 (1). pp. 37-44. DOI: 10.3311/PP.ar.7159

Siemiatycki, E. (2012) A Smooth Ride? From Industrial to Creative Urbanism in Oshawa, Ontario. International Journal of Urban and Regional Research. 37 (5). pp. 1766-1784. DOI: 10.1111/j.1468-2427.2012. 01196.x

Simon, M. (1992) Tradition as interpreted in ecological way of building. Periodica Polytechnica Architecture. 36 (1). pp. 181-183. 